\title{
EPR study of thylakoid membrane dynamics in mutants of the carotenoid biosynthesis pathway of Synechocystis sp. PCC6803*
}

\author{
Kinga Kłodawska', Przemysław Malec', Mihály Kis², Zoltán Gombos² and Kazimierz Strzałka1凶 \\ 1Department of Plant Physiology and Biochemistry, Faculty of Biochemistry, Biophysics and Biotechnology, Jagiellonian University, Kraków; \\ 2Institute of Plant Biology, Biological Research Center, Hungarian Academy of Sciences, Szeged, Hungary
}

EPR spectroscopy using 5-doxylstearic acid (5-SASL) and 16-doxylstearic acid (16-SASL) spin probes was used to study the fluidity of thylakoid membranes. These were isolated from wild type Synechocystis and from several mutants in genes encoding selected enzymes of the carotenoid biosynthesis pathway and/or acyl-lipid desaturases. Cyanobacteria were cultivated at $25^{\circ} \mathrm{C}$ and $35^{\circ} \mathrm{C}$ under different light regimes: photoautotrophically (PAG) and/or in light-activated heterotrophic conditions (LAHG). The relative fluidity of membranes was estimated from EPR spectra based on the empirical outermost splitting parameter in a temperature range from $15^{\circ} \mathrm{C}$ to $40^{\circ} \mathrm{C}$. Our findings demonstrate that in native thylakoid membranes the elimination of xanthophylls decreased fluidity in the inner membrane region under optimal growth conditions $\left(25^{\circ} \mathrm{C}\right)$ and increased it under sublethal heat stress $\left(35^{\circ} \mathrm{C}\right)$. This indicated that the overall fluidity of native photosynthetic membranes in cyanobacteria may be influenced by the ratio of polar to nonpolar carotenoid pools under different environmental conditions.

Key words: spin labels, carotenoid biosynthesis enzymes, lipid desaturases, cyanobacteria

Received: 17 October, 2011; accepted: 01 March, 2012; available on-line: 17 March, 2012

\section{INTRODUCTION}

Carotenoids are pigments essential to the photosynthetic apparatus in all oxygenic photoautotrophic organisms. They are involved in photoprotection, mostly by quenching excited chlorophyll a triplet states which can generate toxic singlet oxygen (Cogdell et al., 2000). Carotenoids are also believed to play an important role in the maintenance of the integrity of the photosynthetic apparatus (Szabo et al., 2005).

The thylakoid membranes are the site of light-dependent reactions of photosynthesis in cyanobacteria. Photosynthetic activity has been found to be significantly altered in Synechocystis mutants blocked at different stages of carotenoid biosynthesis (Fernández-González et al., 1997; Masamoto et al., 2001; Schäfer et al., 2005; Sozer et al., 2010). It has also been reported that a low level of the saturation of thylakoid membrane fatty acids affects the performance of the photosynthetic machinery during exposure to, and recovery from, low temperature stress (Gombos et al., 1992; 1994; 1997; Gombos \& Murata, 1998).

In particular, the RO mutant is not able to synthesize xanthophylls due to a disruption of the genes which encode $\beta$-carotene hydroxylase $\mathrm{CrtR}$ and $\beta$-carotene ke- tolase CrtO. The ROAD mutant has the same characteristic with the additional disruption of the genes which encode acyl-lipid desaturases $\mathrm{A}$ and $\mathrm{D}$, which are responsible for introducing double bonds in the $\Delta 12$ and $\Delta 6$ positions of $\mathrm{C}_{18}$ fatty acids (Wada et al., 1992; Tasaka et al., 1996). The crtH mutant is not able to synthesize cis to trans carotene isomerase. This mutant, when cultivated under LAHG (light-activated beterotrophic growth) conditions, accumulates cis-carotenes and small amounts of trans-carotenes but no $\beta$-carotene and xanthophylls, whereas under PAG (photoautotrophic growth) conditions it is not distinguishable from the wild type (Masamoto et al., 2001). The crtHB mutant is a carotenoid-free mutant with a disruption in the $\mathrm{CrtB}$ gene which encodes phytoene synthase, obtained on crtH background (Sozer et al., 2010).

The use of doxylstearic acid nitroxide probes has facilitated an analysis of the dynamic properties of biological membranes, both in the polar group region and in the central part of the lipid bilayer (Subczyński et al., 1989). Particularly, studies performed in model experimental systems have demonstrated that the presence of elevated concentrations of polar carotenoids (zeaxanthin, violaxanthin) significantly decrease membrane permeability by oxygen (Subczyński et al., 1991).

Here, using those mutant strains referred to above, which show a deficiency in the activity of key enzymes of the carotenoid biosynthesis pathway and/or an altered level of unsaturated fatty acids in membranes (Table 1), we study the effects of carotenoids on the dynamic properties of native thylakoid membranes in the mesophilic cyanobacterium Synechocystis sp. grown in different light conditions at $25^{\circ} \mathrm{C}$ and $35^{\circ} \mathrm{C}$. These temperatures were selected as being within a physiological range.

\section{MATERIALS AND METHODS}

Growth conditions. Synechocystis sp. PCC6803 was cultivated in a BG-11 medium (Allen, 1968) at $25^{\circ} \mathrm{C}$ and $35^{\circ} \mathrm{C}$ under different light regimes: photoautotrophically (PAG) in constant white light with an intensity of $50 \mu \mathrm{mol}$ photons $\mathrm{m}^{-2} \mathrm{~s}^{-1}$ and/or in light-activated heterotrophic conditions (LAHG) with the addition of 5 $\mathrm{mM}$ glucose in complete darkness, except for $10 \mathrm{~min}$ of light with an intensity of $15 \mu \mathrm{mol}$ photons $\mathrm{m}^{-2} \mathrm{~s}^{-1}$, every $24 \mathrm{~h}$ of the culture period, (Anderson \& McIn-

e-mail: kazimierz.strzalka@uj.edu.pl

* Presented at the 16th International Symposium on Carotenoids, 17-22 July, 2011, Kraków, Poland

Abbreviations: 16-SASL, 16-doxylstearic acid; LAHG, light-activated heterotrophic growth; PAG, photoautotrophic growth; WT, wild type; 5-SASL, 5-doxylstearic acid. 
Table 1. Strains of Synechocystis sp. investigated in the study and their features due to gene mutations. See text for details.

\begin{tabular}{|c|c|c|c|}
\hline Strain & Disrupted genes & Phenotype & References \\
\hline WT & - & wild type & \\
\hline RO & $\begin{array}{l}\text { 1. } \beta \text {-carotene hydroxylase } \mathrm{CrtR} \\
\text { 2. } \beta \text {-carotene ketolase } \mathrm{CrtO}\end{array}$ & not able to synthesize xanthophylls & Schäfer et al., 2005 \\
\hline ROAD & $\begin{array}{l}\text { 1. } \beta \text {-carotene hydroxylase CrtR } \\
\text { 2. } \beta \text {-carotene ketolase CrtO } \\
\text { 3. acyl-lipid desaturases A } \\
\text { 4. acyl-lipid desaturases D }\end{array}$ & $\begin{array}{l}\text { 1. not able to synthesize xanthophylls } \\
\text { 2. not able to introduce double bonds in } \Delta 12 \text { and } \Delta 6 \text { posi- } \\
\text { tions of C } 18 \text { fatty acids }\end{array}$ & $\begin{array}{l}\text { Schäfer et al., } 2005-\text { crtRO } \\
\text { Wada et al., } 1992-\Delta \text { desA/ } \\
\text { desD }\end{array}$ \\
\hline crtH & carotene isomerase $\mathrm{crtH}$ & $\begin{array}{l}\text { 1. not able to perform light-independent cis to trans caro- } \\
\text { tene isomerization } \\
\text { 2. under LAHG conditions produces cis-carotenes and } \\
\text { small amounts of trans-carotenes but no xanthophylls, } \\
\text { whereas under PAG conditions is not distinguishable from } \\
\text { the wild type }\end{array}$ & Masamoto et al., 2001 \\
\hline crtHB & $\begin{array}{l}\text { 1. carotene isomerase } \mathrm{crtH} \\
\text { 2. phytoene synthase } \mathrm{crtB}\end{array}$ & $\begin{array}{l}\text { carotenoid-free, not able to synthesize any carotenoid } \\
\text { species }\end{array}$ & Sozer et al., 2010 \\
\hline
\end{tabular}

tosh, 1991). For the crtHB strain, the culture medium was supplemented with kanamycin and spectinomycin in final concentrations of $40 \mu \mathrm{g} \mathrm{mL}^{-1}$. The $\mathrm{crtH}$ strain was grown in the presence of kanamycin $(20 \mu \mathrm{g} \mathrm{mL}-1)$ as a selective marker (Sozer et al., 2010). Cultures were aerated on a gyratory shaker at $100 \mathrm{rpm}$.

Thylakoid isolation. Thylakoid membranes were isolated from wild type and mutant strains according to Komenda \& Barber (1995). Pelleted thylakoids were resuspended in buffer C (20 mM MES, pH 6.5, $10 \mathrm{mM}$ $\mathrm{CaCl}_{2}, 10 \mathrm{mM} \mathrm{MgCl}, 0.5 \mathrm{M}$ mannitol, 20\% (v/v) glycerol, $1 \mathrm{mM}$ PMSF, and $1 \mathrm{mM}$ benzamidine) and stored at $-80^{\circ} \mathrm{C}$.

EPR measurements. Two spin labels were used: 5-doxylstearic acid (5-SASL) reporting on the membrane dynamics close to the lipid headgroup region, and 16-doxyl stearic acid (16-SASL) reporting on the dynamics of the membrane interior. Labeling was performed by vortexing an isolated membrane sample (chlorophyll concentration of $1 \mathrm{mg} \mathrm{mL}^{-1}$ ) with an aliquot of the stock solution of the respective spin label to a final concentration of $7 \times 10^{-4} \mathrm{M}$. The EPR spectra of the spin labeled thylakoid membranes were recorded with a MiniScope EPR Spectrometer (Magnettech, Germany) equipped with a temperature control unit in a temperature range from $15^{\circ} \mathrm{C}$ to $40^{\circ} \mathrm{C}$. The modulation amplitude was 1600 $\mathrm{mG}$ and the microwave power was $5.012 \mathrm{~mW}$. An outermost splitting parameter $\left(2 \mathrm{~A}^{\prime} \|\right)$ was measured from the averaged spectra (10 separate measurements for each temperature), as shown in Fig. 1. The dynamic parameters were calculated following Strzałka et al., (1995).

Pigments and protein determination. The chlorophyll content was calculated from Beer-Lambert's law using its extinction coefficient at $665 \mathrm{~nm}$ (Lichtenthaler, 1987). The total carotenoid content was measured in $80 \%$ acetone and calculated as previously described in Schnarrenberger \& Mohr (1970). The protein concentration in isolated membranes was measured using the Lowry method (Lowry et al., 1951).

\section{RESULTS AND DISCUSSION}

The chlorophyll to protein and total carotenoid to protein ratios $\left(\mu \mathrm{g} \mathrm{mg} \mathrm{m}^{-1}\right)$ were estimated for each examined strain grown at temperatures $25^{\circ} \mathrm{C}$ and $35^{\circ} \mathrm{C}$ (Table 2). The observed chlorophyll/protein ratios for all investigated strains were remarkably higher for cells cultivated at $25^{\circ} \mathrm{C}$ (the temperature optimal for mesophilic cyanobacteria) in comparison to these grown at $35^{\circ} \mathrm{C}$, indicating that the adaptation to mesophilic temperature ranges is not affected by mutations of the enzymes of the carotenoid biosynthesis pathway. Conversely, the RO and ROAD mutants showed a slightly more efficient chlorophyll accumulation at both temperatures in comparison to WT cells. The observed decrease in chlorophyll accumulation at $35^{\circ} \mathrm{C}$ was especially dramatic for cells grown in light activated heterotrophic conditions (crtH and crtHB strains). This effect was accompanied by a significant decrease in total carotenoid accumulation (crtH) or a general inability to synthesize carotenoids (crtHB). Our previous study on a crtHB mutant demonstrated that carotenoids are indispensable constituents of the photosynthetic apparatus, being essential for the efficient synthesis and accumulation of photosynthetic proteins and especially that of PSII antenna subunits (Sozer et al., 2010). Thus, the inability to assemble a photosystem II complex in LAHG conditions may result in a decrease in total chlorophyll accumulation. Also, crtH cells grown photoautotrophically exhibited a slightly lower chlorophyll content in comparison to the other mutants.

The relative carotenoid/protein ratios were higher in cells grown at $25^{\circ} \mathrm{C}$ than $35^{\circ} \mathrm{C}$ except for the $\mathrm{RO}$ and ROAD mutants. In these two mutants, which do not synthesize any xanthophyll species, the total carotenoid content was higher if cells were grown at $35^{\circ} \mathrm{C}$.

Thylakoid membranes isolated from W'T and mutant cells grown at different temperatures and/or light conditions were labeled with nitroxide probes (5-SASL and 16SASL) as described in Materials and Methods. Subsequently,

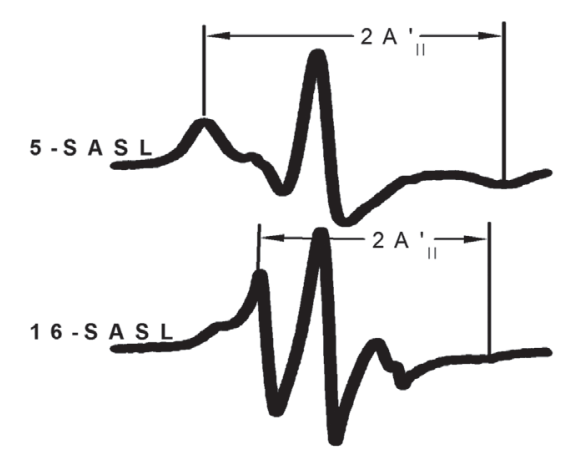

Figure 1. EPR spectra of doxylstearic acid spin probes: 5-SASL and 16-SASL incorporated into thylakoid membrane. The outermost splitting parameter $\left(2 A^{\prime} \|\right)$ is indicated. 

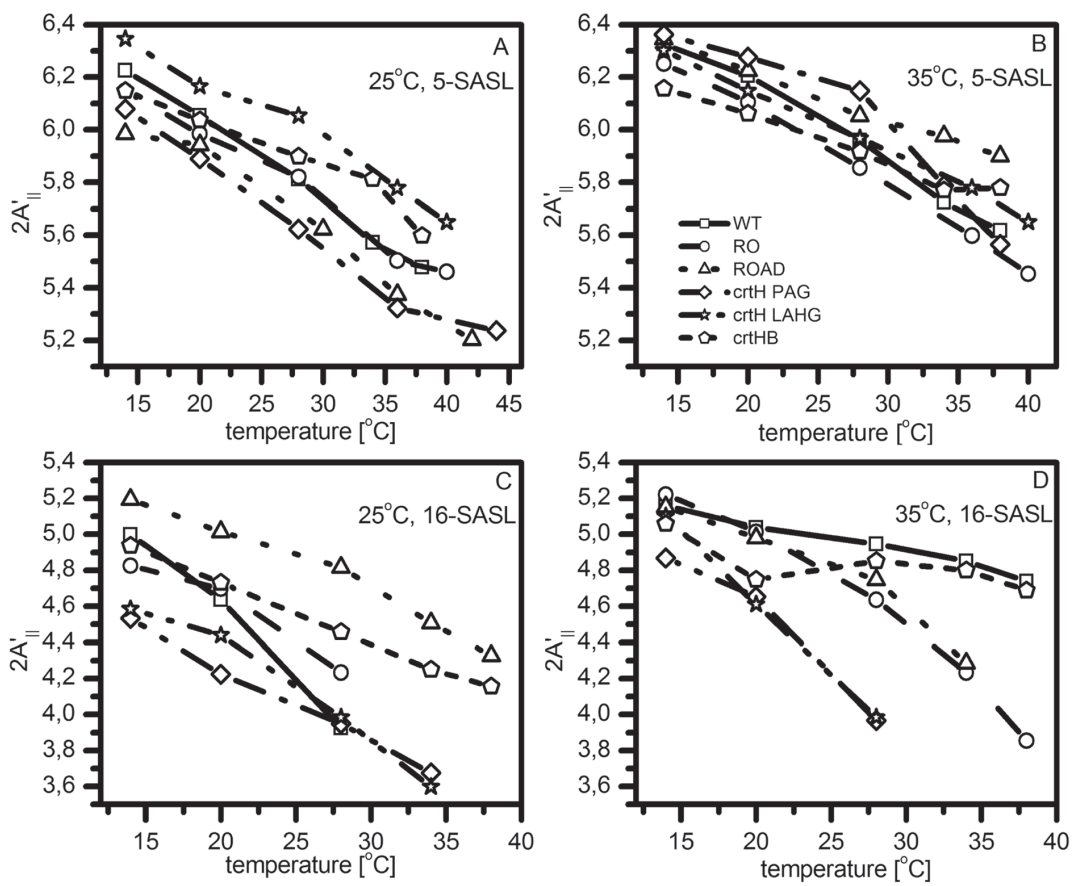

Figure 2. Temperature dependencies of the outermost splitting parameter $\left(2 A^{\prime} \|\right)$ for wild type and mutant strains cultivated at $25^{\circ} \mathrm{C}(\mathrm{A}, \mathrm{C})$ and $35^{\circ} \mathrm{C}(\mathrm{B}, \mathrm{D})$ as calculated for 5-SASL labeled membranes (A, B) and for 16-SASL labeled membranes (C, D). Square, WT; circle, RO; triangle, ROAD; diamond, crtH (PAG); star, crtH (LAHG); pentagon, crtHB (LAHG).

the EPR spectra were recorded and an outermost splitting parameter $2 \mathrm{~A}^{\prime} \|$ was determined for each temperature. The outermost splitting parameter reflects the general mobility of a spin label in the membrane and therefore it may be interpreted as a measure of the relative membrane fluidity (Strzałka et al., 1995). Consequently, the relative changes in $2 \mathrm{~A}^{\prime} \|$ at temperatures from $15^{\circ} \mathrm{C}$ to $40^{\circ} \mathrm{C}$ may reflect the relative "plasticity" of native membranes under physiological conditions. Figure 2 shows the temperature dependencies of $2 \mathrm{~A}^{\prime} \|$ values as measured for 5-SASL and 16-SASL labeled thylakoid membranes isolated from WT and mutant cells grown under different temperature and light conditions.

The relative narrowing of the EPR spectra, attributable to the increased mobility of spin labels in membranes, with an increase in temperature was observed for both W'T and all the mutant strains under investigation. In some cases, however, we were not able to estimate the outermost splitting parameter for temperatures over $30^{\circ} \mathrm{C}$. These effects indicate that, under physiological conditions, cyanobacterial thylakoid membranes became more fluid with an increase in temperature. Interestingly, for W'T membranes the outermost splitting parameter exhibited noticeably higher values for membranes isolated from cells cultivated at $35^{\circ} \mathrm{C}$ (Fig. 2B, D) than at $25^{\circ} \mathrm{C}$ (Fig. 2A, C). This result indicates that growth conditions may affect the fluidity of cyanobacterial thylakoid membranes. The relatively lower fluidity of membranes isolated from cells grown at $35^{\circ} \mathrm{C}$ suggests the existence of mechanisms which make membranes more rigid at higher growth temperatures.

For membranes labeled with 5-SASL, reporting membrane fluidity in the polar group region, the decrease trends observed for outermost splitting values with an increase in temperature were similar, regardless of the cyanobacterial strains analyzed. However, the $2 \mathrm{~A}^{\prime} \|$ values as measured for membranes from $35^{\circ} \mathrm{C}$ were relatively higher in comparison to these observed for membranes from $25^{\circ} \mathrm{C}$, indicating that the polar groups of thylakoids became relatively more rigid at higher temperatures (Fig. $2 \mathrm{~A}, \mathrm{~B})$. Interestingly, the fluidity of membranes in the polar region of the crtH mutant grown at $25^{\circ} \mathrm{C}$ in LAHG conditions was remarkably lower in comparison to these formed under PAG (Fig. 2A).

By contrast, in the inner region of the bilayer (membranes labeled with 16-SASL) there were pronounced differences observed among cyanobacterial strains and growth conditions. The ROAD cells and crtHB cells cultivated at $25^{\circ} \mathrm{C}$ have more rigid thylakoid membranes than the other strains (Fig. 2C). For ROAD cells this can be seen in the whole range of measured temperatures, while in the case of crtHB cells this effect appears only above $25^{\circ} \mathrm{C}$. Among the cells grown at $35^{\circ} \mathrm{C}$, the crtHB mutant, that is not able to synthesize any carotenoid species, along with W'T formed the group with the most rigid membranes which is visible at temperatures above $30^{\circ} \mathrm{C}$. The $\mathrm{RO}$ and $\mathrm{ROAD}$ mutants, which are deficient both in $\beta$-carotene hydroxylase and in $\beta$-carotene ketolase and therefore do not synthesize any xanthophylls, formed a group with medium rigidity of the membranes. The crtH strain, grown under either PAG or LAHG conditions formed a group characterized by the most fluid membranes (Fig. 2D). The differences between

Table 2. Chlorophyll to protein and total carotenoids to protein ratios in all examined strains of Synechocystis sp. Standard deviation (S.D.) values are given.

\begin{tabular}{lcccc}
\hline \multirow{2}{*}{ Strain and light regime } & \multicolumn{2}{c}{ Chlorophyll/protein $\left(\mu \mathrm{g} \mathrm{m}^{-1}\right)$} & \multicolumn{2}{c}{ Total carotenoid/protein $\left(\mu \mathrm{g} \mathrm{mg} \mathrm{mg}^{-1}\right)$} \\
\cline { 2 - 5 } & $25^{\circ} \mathrm{C}$ & $35^{\circ} \mathrm{C}$ & $25^{\circ} \mathrm{C}$ & $35^{\circ} \mathrm{C}$ \\
\hline WT PAG & $6.54 \pm 0.10$ & $4.44 \pm 0.08$ & $4.66 \pm 0.18$ & $1.45 \pm 0.42$ \\
RO PAG & $8.62 \pm 0.16$ & $6.74 \pm 0.12$ & $5.25 \pm 0.49$ & $7.04 \pm 0.59$ \\
ROAD PAG & $9.42 \pm 0.15$ & $6.47 \pm 0.09$ & $3.92 \pm 0.52$ & $4.48 \pm 0.10$ \\
crtH PAG & $5.69 \pm 0.09$ & $3.17 \pm 0.05$ & $4.89 \pm 0.66$ & $1.18 \pm 0.10$ \\
crtH LAHG & $6.06 \pm 0.08$ & $1.18 \pm 0.01$ & $4.15 \pm 0.68$ & $0.29 \pm 0.01$ \\
crtHB LAHG & $7.51 \pm 0.07$ & $1.75 \pm 0.01$ & - & - \\
\hline
\end{tabular}


these groups were especially distinct in the higher temperature range.

The effects of carotenoids on the structural and dynamic properties of lipid membranes have been studied extensively in model experimental systems (see: Gruszecki \& Strzałka, 2005 for a review). In particular, it has been shown that xanthophylls increase membrane fluidity in the ordered phase of the membrane and decrease fluidity in the liquid crystalline phase of membranes formed with phosphatidylocholines (Subczyński et al., 1991). On the other hand, nonpolar $\beta$-carotene has been found to fluidize the well-ordered phase of artificial phosphatidylcholine membranes (Strzałka \& Gruszecki, 1994). Our findings demonstrated that in native thylakoid membranes the elimination of xanthophylls decreased fluidity in the inner membrane region under optimal growth conditions $\left(25^{\circ} \mathrm{C}\right)$ and increased fluidity under sublethal heat stress $\left(35^{\circ} \mathrm{C}\right)$. Thus, the overall fluidity of native photosynthetic membranes in cyanobacteria may be influenced by the ratio of polar to non-polar carotenoid pools under different environmental conditions.

The $2 \mathrm{~A}^{\prime} \|$ values as measured for membranes labeled with 5-SASL showed only slight differences between WT and analyzed mutants, irrespective of growth temperature. By contrast, in 16-SASL labeled membranes the outermost splitting exhibited more pronounced changes among analyzed cyanobacterial strains. Based on these data it can be concluded that under physiological conditions the polar group region in the membrane has similar physical characteristics regardless of the growth temperature, while the interior of the membrane can be modified along with changes in growth conditions to ensure an optimal state of the photosynthetic machinery. In particular, the remarkable decrease in the fluidity of the membrane interior in the ROAD mutant grown under optimal temperature conditions points to the significance of fatty acid desaturation to the physical properties of thylakoid membranes. Fatty acid desaturation has been shown to enhance the ability of the photosynthetic apparatus to tolerate temperature stress (Gombos \& Murata, 1998). Thus, changes in membrane fluidity might be critical for the regulation of the thermal tolerance of photosynthesis.

The results presented in this communication show that doxylstearic acid probe-based EPR spectroscopy provides an insight into the effects of biotic factors, such as the absence of certain carotenoid species or polyunsaturated fatty acids, and of abiotic factors such as light and growth temperature, on the physical properties of thylakoid membranes in Synechocystis sp. The use of spin labels reporting on membrane properties at different depths demonstrated that the elimination both of xanthophylls and/or polyunsaturated fatty acids caused remarkable alterations of the molecular environment mainly in the inner part of lipid bilayers. It has previously been shown that the overall fluidity of thylakoid membranes is dependent on protein-lipid interactions (Kota et al., 2002). However, the detailed mechanisms constituting background of these alterations remain to be determined.

\section{Acknowledgements}

We thank Prof. Kazumori Masamoto (Kumamoto University, Japan) for supplying us the RO and $\mathrm{crtH}$ strains.

This work was supported by the Polish-Hungarian bilateral grant (OMFB-00584/2010 TéT), by the Hungarian Science Foundation to Z.G. (OTKA: grant K 82052) and the Polish Ministry of Science and Higher Education (2010-2011). The support from International Visegrad Fund (grant No. 21120109) is also acknowledged.

\section{REFERENCES}

Allen MM (1968) Simple conditions for growth of unicellular bluegreen algae on plates. J Phycol 4: 1-4.

Anderson SL, McIntosh L (1991) Light-activated heterotrophic growth of the cyanobacterium Synechocystis sp. strain PCC 6803: a blue-lightrequiring process. J Bacteriol 173: 2761-2767.

Cogdell RJ, Howard TD, Bittl R, Schlodder E, Geisenheimer I, Lubitz W ( 2000 ) How carotenoids protect bacterial photosynthesis. Philos Trans R Soc B: Biol Sci 355: 1345-1349.

Fernández-González B, Sandmann G, Vioque A (1997) A new type of asymmetrically acting $\beta$-carotene ketolase is required for the synthesis of echinenone in the cyanobacterium Synechocystis sp. PCC 6803. J Biol Chem 272: 9728-9733.

Gombos Z, Murata N (1998) Genetic engineering of the unsaturation of membrane glycerolipid: effects on the ability of the photosynthetic machinery to tolerate temperature stress. In Lipids in Photosynthesis: Structure, Function, and Genetics, Siegenthaler P-A, Murata $\mathrm{N}$, eds, pp 249-262. Kluwer Academic Publishers, Dordrecht, The Netherlands.

Gombos Z, Wada H, Murata N (1992) Unsaturation of fatty acids in membrane lipids enhances tolerance of the cyanobacterium Synechocystis PCC 6803 to low-temperature photoinhibition. Proc Natl Acad Sci USA 89: 9959-9963.

Gombos Z, Wada H, Murata N (1994) The recovery of photosynthesis from low-temperature photoinhibition is accelerated by the unsaturation of membrane lipids: a mechanism of chilling tolerance. Proc Natl Acad Sci USA 91: 8787-8791.

Gombos Z, Kanervo E, Tsvetkova N, Sakamoto T, Aro E-M, Murata N (1997) Genetic enhancement of the ability to tolerate photoinhibition by introduction of unsaturated bonds into membrane glycerolipids. Plant Physiol 115: 551-559.

Gruszecki WI, Strzałka K (2005) Carotenoids as modulators of lipid membrane physical properties. Biochim Biophys Acta 1740: 108-115.

Komenda J, Barber J (1995) Comparison of psbO and psbH deletion mutants of Synechocystis PCC 6803 indicates that degradation of D1 protein is regulated by the $\mathrm{QB}$ site and dependent on protein synthesis. Biochemistry 34: 9625-9631.

Kota Z, Horvath LI, Droppa M, Horvath G, Farkas T, Pali T (2002) Protein assembly and heat stability in developing thylakoid membranes during greening. Proc Natl Acad Sci USA 99: 12149-12154.

Lichtenthaler HK (1987) Chlorophylls and carotenoids: pigments of photosynthetic biomembranes. Methods Enzymol 148: 350-382.

Lowry OH, Rosebrough NJ, Farr AL, Randall RJ (1951) Protein measurement with the Folin phenol reagent. J Biol Chem 193: 265-275.

Masamoto K, Wada H, Kaneko T, Takaichi S (2001) Identification of the gene required for cis-to-trans carotene isomerization in carotenogenesis of the cyanobacterium Synechocystis sp. PCC6803. Plant Cell Physiol 42: 1398-1402.

Schäfer L, Vioque A, Sandmann G (2005) Functional in situ evaluation of photosynthesis-protecting carotenoids in mutants of the cyanobacterium Synechocystis PCC6803. J Photochem Photobiol B-Biol 78: 195-201.

Schnarrenberger C, Mohr H (1970) Carotenoid synthesis in mustard seedlings as controlled by phytochrome and inhibitors. Planta 94 : 296-307.

Sozer Ö, Komenda J, Ughy B, Domonkos I, Laczkó-Dobos H, Malec P, Gombos Z, Kis M (2010) Involvement of carotenoids in the synthesis and assembly of protein subnits of photosynthetic reaction centers of Synechocystis sp. PCC6803. Plant Cell Physiol 51: 823-835.

Strzałka K, Gruszecki WI (1994) Effect of beta-carotene on structural and dynamic properties of model phosphatidylcholine membranes: I. An EPR spin label study. Biochim Biophys Acta 1194: 138-142.

Strzałka K, Hara-Nishimura I, Nishimura M (1995) Changes in physical properties of vacuolar membrane during transformation of protein bodies into vacuoles in germinating pumpkin seeds. Biochim Biophys Acta 1239: 103-110.

Subczyński WK, Hyde JS, Kusumi A (1989) Oxygen permeability of phosphatidylcholine-cholesterol membranes. Proc Natl Acad Sci USA 86: 4474-4478.

Subczyński WK, Markowska E, Sielewiesiuk J (1991) Effect of polar carotenoids on the oxygen diffusion-concentration product in lipid bilayer. An EPR spin label study. Biochim Biophys Acta 1068: 68-72.

Szabo I, Bergantino E, Giacometti GM (2005) Light and oxygenic photosynthesis: energy dissipation as a protection mechanism photosynthesis: energy dissipation as a protectic

Tasaka Y, Gombos Z, Nishiyama Y, Mohanty P, Ohba T, Ohki K, Murata N (1996) Targeted mutagenesis of acyl-lipid desaturases in Synechocystis: evidence for the important roles of polyunsaturated membrane lipids in growth, respiration and photosynthesis. EMBO J 15: 6416-6425.

Wada H, Gombos Z, Sakamoto T, Murata N (1992) Genetic Manipulation of the Extent of Desaturation of Fatty Acids in Membrane Lipids in the Cyanobacterium Synechocystis PCC6803. Plant Cell Physiol 33: 535-540. 